\title{
CULTIVO in vitro DE TECA (Tectona grandis L.f.): UMA REVISÃO
}

\author{
Dayane Ávila Fernandes ${ }^{1}$, Roberta Santos Souza ${ }^{1}$, Reginaldo Brito da Costa ${ }^{2}$ \\ ${ }^{1}$ Programa Ciências Florestais e Ambientais FENF/UFMT E-mail: dayavila1@ @otmail.com \\ ${ }^{2}$ Faculdade de Engenharia Florestal / UFMT. Av. Fernando Correa da Costa, n ${ }^{\circ} 2367$ - Bairro Boa Esperança, Cuiabá-MT CEP: \\ 78060-900 E-mail: reg.brito.costa@gmail.com
}

\section{RESUMO}

A presente revisão objetivou reunir trabalhos publicados sobre o cultivo in vitro de teca, que ainda carece de maior aporte de dados disponíveis na literatura pertinente, subsidiando os trabalhos relacionados à micropropagação da espécie. A teca tem grande interesse comercial por apresentar características, tais como beleza, resistência, durabilidade e alto valor econômico. É originária do sudeste asiático, porém com plantios estabelecidos em outras partes do mundo. No Brasil, o cultivo de teca iniciou-se no final da década de 60, sendo implantado pela empresa Cáceres Florestal S.A., no município de Cáceres - MT, onde as condições climáticas favoreceram a adaptação e redução do seu ciclo de corte. A produção de mudas através da propagação clonal tem se mostrado vantajosa devido à multiplicação de matrizes de alta qualidade, em curto período de tempo e em escala comercial. Constatou-se que existem poucos estudos em nível nacional e internacional publicados sobre a micropropagação de teca, provavelmente pelo fato de que as empresas privadas que desenvolvem pesquisas para o avanço da tecnologia utilizada na propagação de indivíduos geneticamente superiores, não divulgarem os resultados, mantendo-os em segredo comercial. De maneira geral, as pesquisas realizadas na área de cultivo in vitro da teca determinaram o melhor protocolo de micropropagação para a espécie, avaliando as fases de assepsia, multiplicação e enraizamento em laboratório ou viveiro, buscando, dessa forma, estabelecer plantios mais produtivos.

Palavras-chave: micropropagação, melhoramento genético, explantes, teca

\section{In vitro CULTIVATION OF TEAK (Tectona grandis L.f.): A REVIEW}

\section{ABSTRACT}

This review aimed at gathering information specifically focused on in vitro cultivation of teak (Tectona grandis L.f.). Teak is of great commercial interest for presenting characteristics such as beauty, endurance, durability and high economic value. It is native from Southeast Asia, but it has plantations established in other parts of the world. In Brazil, the cultivation of teak began in the late 60's, being implemented by the company Cáceres Florestal SA, at Cáceres, State of Mato Grosso, Brazil, where climatic conditions favored adaptation and reduction of time to harvest. Seedling production through clone propagation has proven to be valuable because one replicates high quality parental trees in a short time. The few studies published on micropropagation of teak may probably be due to the fact that private companies, sponsoring technology research on propagation of genetically superior individuals, do not disclose their findings for commercial reasons. As a whole trials conducted for in vitro cultivation of teak intend to find out the best micropropagation protocols, evaluating asepsis, multiplication and rooting in laboratory or nursery, aiming at contributing for better productive plantations.

Key words: micropropagation, genetic improvement, explants, teak 


\section{INTRODUÇÃO}

A teca (Tectona grandis L.f.) é uma espécie arbórea que combina beleza, resistência e durabilidade, sendo considerada uma das madeiras mais valiosas do mundo.

A produção de mudas pode ser feita através do plantio do fruto inteiro, pois as sementes que estão no seu interior são pequenas e delicadas dificultando sua propagação direta. A mistura genética entre as variadas matrizes, que pode ocorrer no período de floração através da polinização, pode ser um fator considerável na seleção de sementes de qualidade (Cáceres Florestal, 2000). Devido a esses cruzamentos, os aspectos morfológicos apresentados por uma matriz selecionada podem não ser expressos em seus descendentes. Neste sentido, a quantidade de sementes produzidas por árvore é reduzida e as taxas de germinação são baixas, variando de 20 a $25 \%$ (Monteuuis \& Maitre, 2007). Isso remete à necessidade do desenvolvimento de técnicas de propagação vegetativa para tornar sua produção eficiente e economicamente viável. A micropropagação torna-se uma alternativa para a obtenção de mudas de alta qualidade, com características desejáveis, em curto período de tempo e em escala comercial. Diversas pesquisas têm sido realizadas no sentido de manipular o ambiente de cultivo, objetivando otimizar a técnica, tornando-a economicamente viável e mais acessível. Além disso, é muito importante estabelecer protocolos de micropropagação para cada espécie. O sucesso da técnica de clonagem tem como seu ponto de partida, a recomendação de um protocolo de assepsia e estabelecimento in vitro com o maior número de explantes, menor produção de compostos fenólicos (oxidação) e com maior sobrevivência para as etapas seguintes (Fermino Junior et al., 2009). Alguns trabalhos envolvendo estudos relacionados ao cultivo in vitro foram realizados com diversas espécies, tais como Matricaria recutita (Cattelan et al., 2007), Thymus vulgaris L. (Bandeira et al., 2007), Pfaffia glomerata (Spreng.) Pedersen (Nicoloso et al., 2001; Nicoloso et al., 2003; Skrebski et al., 2004; Maldaner et al., 2006; Maldaner et al., 2007), Dyckia maritima (Silva et al., 2006), Oncidium baueri (Sorace et al., 2007), entre outros.

No caso da teca, observa-se uma carência de pesquisas, voltadas especificamente ao cultivo in vitro. $\mathrm{O}$ maior aporte de informações advém de alguns trabalhos publicados em revistas internacionais (Rosero \& Ramos, 1998; Daquinta et al., 2001; Rodríguez et al., 2002; Tiwari et al., 2002; Abdelnour \& Muños, 2005; Shirin et al., 2005; Gyves et al., 2007; Akram \& Aftab, 2009; Nor Aini et al., 2009). Dessa forma, a contribuição de pesquisas brasileiras no meio científico mundial se mostra incipiente.

Além disso, Costa et al., (2007) ressalta que existe uma carência em programas de melhoramento genético de teca no Brasil apontando para uma necessidade premente de se estabelecer uma rede experimental, na qual haveria intercâmbio de informações e pesquisas entre as instituições de ensino e empresas privadas envolvidas no cultivo da espécie. A partir desta rede seria possível obter resultados relevantes e estabelecer um programa de melhoramento. Nessa linha inserem-se pesquisas que produzam o desejável avanço do cultivo in vitro da teca como ferramenta importante para programas de melhoramento da espécie.

Torna-se importante a divulgação de estudos que verifiquem a viabilidade do estabelecimento de plantios clonais de teca, além de uma estratégia de conservação de genótipos valiosos para programas de melhoramento, inclusive despertando a 
discussão sobre esse assunto (Palanisamy et al., 2009).

Neste contexto, a presente revisão objetivou reunir trabalhos publicados sobre o cultivo in vitro de teca, que ainda carece de maior aporte de dados disponíveis na literatura pertinente, subsidiando os trabalhos relacionados à micropropagação da espécie.

\section{A ESPÉCIE}

A teca (Tectona grandis L.f.) é uma espécie arbórea decídua de floresta tropical, pertencente à família Lamiaceae (Kew, 2009). Esta espécie em sua região de origem pode desenvolver indivíduos de até 60 metros de altura, dotados ou não de raízes tabulares (Krishnapillay, 1999). Enquanto que no Brasil, o tamanho varia entre 20 e 35 $\mathrm{m}$ de altura e $0,95 \mathrm{~m}$ de diâmetro, na idade adulta.

As folhas da teca são opostas, elípticas, coriáceas e ásperas no tato, dotadas de pecíolos curtos ou ausentes e ápice e base agudos. Nos indivíduos adultos as folhas, em média, possuem 30 a $40 \mathrm{~cm}$ de comprimento por $25 \mathrm{~cm}$ de largura. No entanto, nos indivíduos mais jovens, com até 3 anos de idade, as folhas podem atingir o dobro dessas dimensões.

As flores apresentam características morfológicas tais como: folhas coriáceas que medem de 30 a $60 \mathrm{~cm}$ de comprimento por 20 a $35 \mathrm{~cm}$ de largura, tornando a árvore sombreante desde a fase juvenil (Angeli \& Stape, 2003). São do tipo actinomórfica e hermafrodita normalmente possuem seis pétalas e um único verticilo, com pistilos compostos de um ovário com quatro óvulos e um estilo com o estigma bifurcado. Estilo e os estames possuem cerca de $6 \mathrm{~mm}$ de comprimento e o diâmetro da corola é de 6-8 $\mathrm{mm}$.

Os frutos são do tipo drupa, cilíndricos, de cor marrom e apresentam quatro cavidades, dentro das quais estão as sementes (uma por cavidade); porém, nem todas germinam. Cada fruto possui em seu interior de 1 a 4 sementes. Este conjunto está incluso em um invólucro vesicular de consistência membranosa (Schubert, 1974). A primeira frutificação ocorre aos 5 ou 6 anos de idade. Perde as folhas durante a estação seca, sendo chamada caducifólia ou decídua (Angeli \& Stape, 2003). Tal característica contribui na redução da perda de água para o ambiente através da transpiração exercida pelas folhas.

Conforme Higuchi (1979), a madeira da teca possui alburno amarelado ou esbranquiçado, geralmente delgado, contrastando com o cerne que é castanhoamarelado. Apresenta anéis de crescimento nítidos e diferenciados nos cortes transversais. O lenho é moderadamente duro, oleoso ao tato (Matricardi, 1989).

Diversos autores, dentre eles, Berg (1953), Banijbhatana (1957), Mello (1963), Jacobs (1973), Schubert (1974), Ramakrishina (1978), Pandey \& Brown (1999), Krishnapillay (1999), Killmann \& Hong (1999), Balooni (1999), Enters (1999) e Mittelman (1999) ressaltam a importância econômica da teca e as qualidades físicomecânicas, bem como as possibilidades de uso da madeira.

Matricardi (1989) ressalta que a madeira da teca aceita secagem ao ar livre e em estufa, com perdas e depreciações mínimas decorrentes deste processo, tais como rachaduras e empenamentos, em função de seu baixo coeficiente de contração e excelente estabilidade. $\mathrm{O}$ autor salienta que o seu teor de sílica é variável, permite serragem, aplainamento, desenrolamento e laminação de maneira satisfatória.

A madeira da teca alcança bons preços e, compete, no momento em igualdade de situação com madeiras consideradas mundialmente nobres, em especial quando comparada ao mogno. No entanto, na indústria naval o preço da teca sobressai àquelas indicadas para esta 
utilização. Krishnapillay (1999) reconhece a durabilidade e trabalhabilidade da espécie, abordando aspectos silviculturais e manejo de plantios de teca.

Inicialmente, os plantios de teca limitavam-se aos países da Ásia Tropical, principalmente Índia, Myanmar e Tailândia, cujo objetivo era compensar o esgotamento das populações naturais de teca que eram exploradas de forma desordenada. Posteriormente, iniciou-se o cultivo em novas zonas tropicais, particularmente na África Ocidental, América Central e América do Sul, sobretudo na Costa Rica e no Brasil, onde os plantios são caracterizados pela elevada densidade de indivíduos e com rotações mais curtas que as praticadas no sudeste asiático (Figueiredo et al., 2005).

A teca desenvolve-se bem em regiões de clima quente, com temperaturas médias anuais acima de $24{ }^{\circ} \mathrm{C}$, com pluviosidade acima de $1200 \mathrm{~mm}$ anuais, em solo profundo, drenado, arejado e razoável fertilidade, demonstram também boa resistência ao fogo (Figueiredo, 2001). Conforme Macedo et al. (2005), trata-se de uma árvore de grande porte, de rápido crescimento, produtora de madeira nobre. Possui tronco retilíneo, fácil de cultivar, pouco sujeito às pragas e doenças. Seu cerne possui tectoquinona, um preservativo natural contido nas células da madeira que a previne do ataque de pragas. O caúcho é outra substância que está presente no cerne e também no alburno, ajudando na redução e absorção de água, assim como na lubrificação das superfícies (Angeli \& Stape, 2003)

A madeira da teca apresenta alta durabilidade, resistência, além da beleza estética, mundialmente recebe uma variedade de usos. A beleza é representada por sua coloração diferenciada, apresentando-se clara na região do alburno que faz contraste com o cerne, cuja cor é marrom viva e brilhante. É uma madeira leve que apresenta boa resistência ao peso, tração e flexão. Possui grande estabilidade durante o período de secagem, quase não empena, contrai-se pouco e resiste à variação de umidade no ambiente. A beleza exótica faz a teca ser muito procurada na fabricação de móveis finos, utilizados para efeito decorativo de interiores luxuosos. Além disso, a resistência e durabilidade fazem com que possa também ser utilizada na construção naval e esquadrias de alto padrão, laminação e compensados, lenha e carvão vegetal (Angeli \& Stape, 2003; Macedo et al., 2005).

Diante de tais características, o reflorestamento da teca é atualmente considerado uma ótima opção de investimento. A espécie adaptou-se muito bem a algumas regiões do Brasil onde as condições climáticas se assemelham aquelas encontradas nos países de origem, inclusive com valor econômico mais elevado em comparação ao mogno amazônico (Angeli \& Stape, 2003).

No Brasil, o cultivo de teca iniciou-se ao final da década de 60, sendo implantado pela empresa Cáceres Florestal S.A., no município de Cáceres - MT (Matricardi, 1989). A introdução aconteceu em 1968 e o reflorestamento em escala comercial ocorreu a partir de 1971 (Caldeira \& Oliveira, 2008).

Em 1968, com o propósito de assegurar a disponibilidade sustentada de madeira para sua indústria, a empresa deu início a pesquisa e experimentação do reflorestamento. Foram testadas diversas espécies nativas e exóticas, com destaque para o mogno. A espécie mostrou ser uma planta sensível e de difícil estabelecimento e condução. A teca sobressaiu às demais espécies testadas, por sua rusticidade, rápido crescimento inicial e boa forma florestal. Contribuíram também para sua seleção a 
grande procura e o elevado preço que sua madeira já experimentava no mercado internacional (Cáceres Florestal, 2005). Uma inovação marcante que caracteriza o plantio em Cáceres é a redução no prazo do ciclo de corte, de 20 a 25 anos. Nas demais plantações no exterior, o ciclo varia entre 60 e 80 anos (Angeli \& Stape, 2003).

A origem das matrizes introduzidas no Brasil ainda é desconhecida, tendo-se somente registro de materiais provenientes da Índia que foram utilizados em plantios de teca realizados no Jardim Botânico do Rio de Janeiro e no Horto Florestal de Rio Claro (Matricardi, 1989). Conforme a ABRAF (2009), os estados brasileiros com os maiores plantios de teca são o Mato Grosso, a Amazônia e o Acre, com a superfície plantada abrangendo cerca de 58.000 ha.

As informações disponíveis para subsidiar programas silviculturais para a espécie adaptados às diversas condições regionais ainda são incipientes no país (Tonini et al., 2009). Dados de crescimento e produção ainda são escassos nos trópicos e muito reduzidos no país, mostrando a importância de realizar e publicar levantamentos, uma vez que a produção em larga escala aumenta a cada dia.

No estado de Mato Grosso os primeiros plantios comerciais ocorreram no início da década de setenta, no município de Cáceres. Na primeira metade da década de noventa as áreas de florestas de teca não passavam de 2.000 hectares, sendo a quase totalidade de uma única empresa. Conforme dados obtidos da Empresa Floresteca (Romio, 2006), a sua área plantada perfaz mais de 20 mil hectares, sendo que as primeiras mudas foram estabelecidas em 1994.

Em relação ao melhoramento genético da espécie, no Brasil aparentemente não existem programas com a teca, de forma que a variação genética existente entre e dentro de populações não tem sido explorada adequadamente (Costa et al., 2007).

\section{PRODUÇÃO E PROPAGAÇÃO DE MUDAS}

A produção de mudas pode ser feita através do plantio direto do fruto, pois as sementes são muito pequenas e delicadas, dificultando sua propagação. Alguns aspectos morfológicos desejáveis em uma árvore matriz devem ser considerados na seleção de sementes de qualidade. Porém, o fato de uma árvore apresentar uma estrutura ideal para que seus frutos sejam selecionados, isso não é garantia de que seus descendentes apresentarão as mesmas características, pois são realizados cruzamentos durante o período de floração através da polinização. Com isso, ocorre a mistura de características genéticas entre as variadas matrizes (Cáceres Florestal, 2000).

O cultivo de teca por sementes é amplamente difundido nos trópicos (Yasodha et al., 2004). A produção de mudas nesse caso é pouco eficiente, em função da reduzida quantidade de sementes por árvore e baixas taxas de germinação (Monteuuis \& Maitre, 2007). Diante deste quadro, há uma procura por outras opções de produção que impulsionam o desenvolvimento de novas técnicas de reprodução vegetativa.

A biotecnologia tem sido um instrumento de resgate e preservação da biodiversidade da floresta tropical (Daquinta et al., 2001), e a clonagem tem contribuído para propagação em larga escala de genótipos superiores. A propagação clonal emerge nesse cenário como uma estratégia que apresenta ganhos consideráveis na obtenção das mudas, pois a técnica proporcionou a maximização da produção, mantendo características que desejáveis (Higashi et al., 2000). A micropropagação de espécies lenhosas vem sendo estudada há várias décadas e tem como objetivo básico o estabelecimento de uma metodologia de multiplicação clonal de indivíduos superiores. A fonte de explantes deve ser 
cuidadosamente selecionada, uma vez que o tipo de material utilizado, muitas vezes, determina o grau de sucesso da técnica.

A micropropagação ou propagação in vitro permite a produção massal de indivíduos com características genéticas desejáveis e alto padrão de sanidade das mudas, em um curto período de tempo. Neste aspecto, o emprego de técnicas biotecnológicas em espécies florestais, especialmente em áreas reflorestadas, poderá aumentar a disponibilidade de madeira, reduzindo a pressão sobre as florestas nativas (Fermino Junior et al., 2009).

Portanto, a produção de mudas clonais de teca para plantios florestais constitui-se em uma promissora contribuição para o setor florestal do Brasil, permitindo o desenvolvimento de conservação, utilização e proteção de recursos florestais (Viana et al., 1999).

O que dificulta e atrasa o intercâmbio de informações entre os pesquisadores nacionais e a comunidade científica internacional e a falta de publicação de dados referentes a esse assunto.

\section{CULTURA DE TECIDOS VEGETAIS}

A cultura de tecidos vegetais envolve um processo no qual pequenos fragmentos de tecido vivo (chamados de explantes), são isolados, desinfestados e cultivados assepticamente, por períodos indefinidos num meio de cultura apropriado (Andrade, 2002). O sucesso da técnica de micropropagação tem como seu ponto de partida a recomendação de um protocolo de assepsia e estabelecimento in vitro, com o maior número de explantes assépticos, menor produção de compostos fenólicos (oxidação) e com maior sobrevivência dos explantes para as etapas seguintes (Fermino Junior et al., 2009).

Para Grattapaglia \& Machado (1998), o procedimento da clonagem de forma eficiente, depende do controle de um grande número de variáveis, pois cada espécie (ou clone) apresenta características únicas e, portanto, as necessidades para o cultivo in vitro também tendem a ser únicas. Uma das variáveis a serem controladas, está relacionada ao meio de cultura no qual o explante será inoculado, pois representa a base nutritiva necessária para seu desenvolvimento. Porém, a composição do meio de cultivo não é considerada a variável determinante para o sucesso da micropropagação, devido ao conhecimento difundido da função dos componentes utilizados e à repetibilidade a qual uma determinada formulação é submetida. Dessa forma, o grande desafio encontra-se na manipulação do material vegetal, desde antes de excisar o explante inicial, em todos os passos do cultivo, até o transplantio da plântula produzida (Grattapaglia \& Machado, 1998).

Contudo, o sucesso da micropropagação não se deve somente aos fatores inerentes ao tecido vegetal (genéticos e fisiológicos), mas também às condições térmicas e luminosas nas quais a cultura é mantida, e ainda ao meio de cultura apropriado que possibilita a indução, a multiplicação e o crescimento das brotações adventícias (Nagao et al., 1994). As exigências nutricionais requeridas para $\mathrm{o}$ crescimento de um tecido cultivado in vitro, variam entre as espécies, entre as variedades e até mesmo dentro da própria planta, mostrando a necessidade de adequar o meio de cultura para cada caso.

Os meios de cultura, além de fornecer as substâncias essenciais para o crescimento, também controlam o padrão de desenvolvimento in vitro (Caldas et al., 1990). Alguns desses meios foram especificamente desenvolvidos para fornecer os requisitos particulares à espécie trabalhada, como o meio básico de cultura de Murashige \& Skoog (1962), desenvolvido inicialmente para o tecido medular de Nicotiana tabacum. Assim, para cada 
espécie cultivada, o meio de cultura é adaptado de acordo com as necessidades do explante, pois existem diferenças fisiológicas entre e até dentro das espécies.

Percebe-se que o cultivo in vitro de plantas é uma prática que reúne uma série de fatores e de condições que são essenciais para o êxito da técnica de micropropagação. Cada autor relaciona o sucesso a um fator ou outro, porém o que se observa é que todos estes fatores possuem importância compartilhada, pois se um deles não for executado de forma adequada o produto final pode não ser o esperado.

Segundo Carvalho \& Vidal (2003), na micropropagação, podem ser utilizados os seguintes métodos: $i$ ) proliferação de gemas axilares; ii) indução de gemas adventícias por organogênese direta ou indireta; iv) embriogênese somática; v) embriogênese direta; vi) embriogênese indireta;

A proliferação de gemas axilares é, geralmente, preferida na micropropagação de espécies lenhosas, muito utilizada para o gênero Eucalyptus (Xavier et al., 2007). Os segmentos nodais ou apicais são apropriados para a utilização como fonte de explantes por apresentarem as seguintes vantagens: adaptação às condições in vitro; alto grau de valor genético da planta-matriz; maior garantia de regeneração e economia de espaço para armazenamento em salas de crescimento (Carvalho \& Vidal, 2003).

Outra vantagem do uso desse sistema está relacionada à possibilidade de propagação de árvores selecionadas em qualquer idade, constituindo-se em uma alternativa em relação aos métodos clássicos de propagação vegetativa. A proliferação de gemas axilares de várias espécies de Eucalipto mostrou-se adequada no rejuvenescimento de clones selecionados, com experiências relatadas com os mais diversos objetivos almejados (Xavier et al., 2007).

\section{CULTIVO in vitro DE TECA}

Diante das vantagens de utilizar a teca nas práticas de reflorestamento como uma atividade rentável e promissora, bem como mostrar o sucesso proporcionado pela clonagem vegetal através da micropropagação, apresentam-se estudos relacionados especificamente ao cultivo in vitro de teca.

Pesquisas que visaram estabelecer um protocolo de propagação in vitro de teca foram desenvolvidos por Rosero \& Ramos (1998) e Daquinta et al. (2001), dentre os experimentos realizados em cada fase de cultivo destacou-se a fase de multiplicação na qual ambos testaram o efeito de BAP (Benzilaminopurina) e KIN (Cinetina) e obtiveram melhor resultado na combinação de 1,0 mg. $\mathrm{L}^{-1}$ de BAP + 0,5 mg. $\mathrm{L}^{-1}$ de KIN, mostrando o bom desempenho no uso desses reguladores de crescimento. Contudo, Rodríguez et al. (2002) observaram que no meio MS suplementado com 0,5 mg. $\mathrm{L}^{-1}$ BAP e $0,25 \mathrm{mg} . \mathrm{L}^{-1} \mathrm{KIN}$, obteve-se indução de brotação. Ao utilizar a metade da concentração dessas citocininas ou o meio sem reguladores de crescimento, a regeneração foi nula.

Já Tiwari et al. (2002), testaram o efeito do BAP combinado com o AIA (Ácido Indolacético), sendo que o meio suplementado com 22,2 $\mu \mathrm{M}$ de BAP e 0,0 ou $0,57 \mu \mathrm{M}$ de AIA (Ácido Indolacético) produziu maior número de brotações quando comparado aos demais tratamentos. A interação entre o BAP e o AIA mostrou-se significativa para a formação de brotos e posterior alongamento neste caso.

Ao realizar um estudo para avaliar a técnica de micropropagação, Abdelnour \& Muños (2005) observaram que na fase de multiplicação, a adição de $1 \mathrm{mg} . \mathrm{L}^{-1}$ e 2 $\mathrm{mg} . \mathrm{L}^{-1}$ de BA (Benziladenina) favoreceu o desenvolvimento de uma maior porcentagem 
plântulas (64\% e $71 \%$ respectivamente), aumentando também o número de entrenós de 2 e 3, respectivamente. Quando combinado o BA $\left(2 \mathrm{mg} . \mathrm{L}^{-1}\right)$ e o AIA $(0,02$ $\left.\mathrm{mg} . \mathrm{L}^{-1}\right)$, obteve-se a maior porcentagem de multiplicação de brotos $(80 \%)$ e maior média de entrenós com 4,6. Durante este estudo mostrou-se a viabilidade da utilização da micropropagação de teca, estabelecendo uma metodologia básica que permitiu a obtenção de altas taxas de sucesso nas diferentes fases do processo.

O experimento desenvolvido por Akram \& Aftab (2009), mostrou um método eficiente para a propagação clonal in vitro e estabelecimento de brotos de madeira macia de gemas epicórmicas de teca. Os resultados obtidos mostraram que na fase de multiplicação dos ápices, o maior número de brotos foi de 42,80, com comprimento de $54,33 \mathrm{~mm}$ da parte aérea, no tratamento MS (Murashige \& Skoog, 1962) + BAP $(8,8$ mmol. $\left.\mathrm{L}^{-1}\right)+$ AIB $\left(2 \mathrm{mmol} \cdot \mathrm{L}^{-1}\right)$. Testando o efeito de ANA (Ácido Naftalenolacético) e BAP, Fermino Junior et al. (2009), observaram 0 melhor resultado na combinação de $0,5 \mu \mathrm{M}$ de ANA $+2,2 \mu \mathrm{M}$ de BAP, com 1,75 de brotos, enquanto que nas oriundas de plantas adultas (1,75 brotos) foi de $0,5 \mu \mathrm{M}$ de ANA $+4,4 \mu \mathrm{M}$ de BAP em meio MS (Murashige \& Skoog, 1962).

A micropropagação envolve diversas fases para o estabelecimento da cultura in vitro, sendo assim, Shirin et al. (2005), descreveram um procedimento para a propagação clonal de teca testando o enraizamento in vitro. Apresentando melhor resultado com o meio $\mathrm{MS}$ líquido suplementado com $15 \mu \mathrm{M}$ M de ANA (Ácido Naftalenolacético), com 66,66\% de brotos enraizados, com 1,60 raízes por broto. Contudo, Gyves et al. (2006), obtiveram $100 \%$ de brotos enraizados no meio de cultura MS modificado contendo AIB (0,5 mg. $\left.\mathrm{L}^{-1}\right)$ combinado com putrescina $(160 \mathrm{mg}$. $\left.\mathrm{L}^{-1}\right)$. Em outro caso, Nor Aini et al. (2009) testou os efeitos do ambiente claro e escuro combinado com concentrações de AIB (Ácido Indolbutírico), dentre os resultados, observaram que os explantes no regime de luz produziram maior número de raízes e comprimento em baixas concentrações de AIB $\left(0,5\right.$ e $\left.1,0 \quad \mathrm{mg} . \mathrm{L}^{-1}\right)$. Inversamente, quando incubadas no escuro, o maior número médio de raízes e comprimento foram obtidos em concentrações maiores de AIB (2,0 e 3,0 mg. $\left.\mathrm{L}^{-1}\right)$. Estes resultados mostraram que o AIB foi necessário para $o$ enraizamento no regime claro e escuro, sendo a concentração ótima de $2,0 \mathrm{mg} . \mathrm{L}^{-1}$.

Fernandes et al. (2009), testaram diferentes tipos de vedação de frascos e concentrações de sacarose no cultivo in vitro de teca. Apenas a variável matéria seca apresentou interação significativa entre os fatores (vedação $\mathrm{X}$ sacarose), sendo os melhores resultados obtidos na combinação da TPS (tampa simples) + sacarose $(18,24 \mathrm{e}$ 30 g. $\mathrm{L}^{-1}$ ), e na combinação da TPF (tampa plástica com filtro) + sacarose (12 e 18 g.L $\left.{ }^{1}\right)$. Observou-se que é possível reduzir a concentração de sacarose, sem comprometer o desenvolvimento da teca. Tambarussi (2009) objetivou estudar a organogênese in vitro de teca visando desenvolver um método de regeneração eficiente. Ao testar a eficiência do meio de cultura, verificou que o meio MS (Murashige \& Skoog, 1962) apresentou maior crescimento das plântulas média de 4,0 gemas internodais, já o meio JADS (Correia, 1993) e o WPM (Lloyd e Mccown, 1980) apresentaram 6,35 e 2,95 respectivamente. $\mathrm{O}$ meio $\mathrm{MS}$ apresentou melhores resultados para a teca e já foi confirmado como melhor para outras espécies lenhosas (Kushalkar \& Sharon, 1996; Tiwari et al., 2002). Além disso, ao testar a organogênese obteve $70 \%$ de regeneração em nó cotiledonar em meio MS com concentração de $1,0 \mathrm{mg} \cdot \mathrm{L}^{-1}$ de BAP + $0,5 \mathrm{mg} . \mathrm{L}^{-1}$ de $\mathrm{GA}_{3}$.

Andrade (2010) realizou um estudo para testar a indução de rejuvenescimento através da enxertia seriada e 
micropropagação. Cerca de $84 \%$ dos meristemas para cada tratamento sobreviveram sem oxidação e/ou contaminação, não havendo diferença relacionada ao tipo de material genético utilizado. $\mathrm{Na}$ fase de estabelecimento observou-se que houve significância tanto entre os materiais genéticos quanto das concentrações de BAP, para todas as variáveis, apenas com exceção da variável tamanho que não demonstrou diferença entre os materiais genéticos. $\mathrm{Na}$ fase de multiplicação e rejuvenescimento, observouse que com o aumento do número de subcultivos, houve diminuição das brotações no clone B. Assim, apenas a testemunha e o clone A seguiram até o quinto subcultivo. Não houve diferença significativa entre os subcultivos para a testemunha, porém, o clone A apresentou diferença, apresentando melhor resultado para o terceiro, quarto e quinto subcultivos quando comparados ao primeiro e segundo.

De maneira geral os estudos se complementam e são importantes, pois existe o interesse em melhorar o método de propagação vegetativa e a tentativa de otimizar o processo de cultivo in vitro. Para melhor visualização e posterior consulta dos trabalhos completos de acordo com o interesse do leitor, as pesquisas descritas são apresentadas de forma resumida na Tabela 1 . 
Tabela 1. Artigos relacionados com o cultivo in vitro de teca.

\begin{tabular}{|c|c|c|}
\hline Autores / Ano & Título & Local \\
\hline Rosero \& Ramos 1998 & $\begin{array}{l}\text { Micropropagacíon clonal in vitro de } \\
\text { árboles seleccionados de Tectona grandis } \\
\text { L.(Teca). }\end{array}$ & $\begin{array}{l}\text { Santo Domingo de } \\
\text { Los Colorados, } \\
\text { Equador }\end{array}$ \\
\hline Daquinta et al. 2001 & $\begin{array}{l}\text { Micropropagación de la teca (Tectona } \\
\text { grandis L.F.). }\end{array}$ & $\begin{array}{l}\text { Ciego de Avila, } \\
\text { Cuba }\end{array}$ \\
\hline Rodríguez et al. 2002 & $\begin{array}{l}\text { Morfogénesis in vitro de Teca (Tectona } \\
\text { grandis L.). }\end{array}$ & $\begin{array}{l}\text { Ciego de Avila, } \\
\text { Cuba }\end{array}$ \\
\hline Tiwari et al. 2002 & $\begin{array}{l}\text { An improved micropropagation protocol } \\
\text { for teak. }\end{array}$ & $\begin{array}{l}\text { Jabalpur, } \\
\text { Índia }\end{array}$ \\
\hline Abdelnour \& Muños 2005 & $\begin{array}{l}\text { Micropropagación de teca (Tectona } \\
\text { grandis L.f.). }\end{array}$ & $\begin{array}{l}\text { Cartago, } \\
\text { Costa Rica }\end{array}$ \\
\hline Shirin et al. 2005 & $\begin{array}{l}\text { In vitro clonal propagation of mature } \\
\text { Tectona grandis through axillary bud } \\
\text { proliferation. }\end{array}$ & $\begin{array}{l}\text { Maharashtra, } \\
\text { India }\end{array}$ \\
\hline Gyves et al. 2007 & $\begin{array}{l}\text { Efficient method of micropropagation and } \\
\text { in vitro rooting of teak (Tectona grandis } \\
\text { L.) focusing on large-scale industrial } \\
\text { plantations. }\end{array}$ & $\begin{array}{l}\text { Java, } \\
\text { Indonésia }\end{array}$ \\
\hline Fernandes et al. 2009 & $\begin{array}{l}\text { Cultivo in vitro de Tectona grandis L.f. } \\
\text { submetido a diferentes tipos de vedação } \\
\text { dos frascos e concentrações de sacarose. }\end{array}$ & $\begin{array}{l}\text { Mato Grosso, } \\
\text { Brasil }\end{array}$ \\
\hline Akram \& Aftab 2009 & $\begin{array}{l}\text { An efficient method for clonal } \\
\text { propagation and in vitro establishment of } \\
\text { softwood shoots from epicormic buds of } \\
\text { teak (Tectona grandis L.). }\end{array}$ & $\begin{array}{l}\text { Lahore, } \\
\text { Paquistão }\end{array}$ \\
\hline Tambarussi 2009 & $\begin{array}{l}\text { Desenvolvimento de metodologias } \\
\text { biotecnológicas para a micropropagação, } \\
\text { regeneração e transformação genética de } \\
\text { teca (Tectona grandis L. f) visando } \\
\text { resistência a Hyblaea puera. }\end{array}$ & $\begin{array}{l}\text { São Paulo, } \\
\text { Brasil }\end{array}$ \\
\hline Fermino Junior et al. 2009 & $\begin{array}{l}\text { Estabelecimento, germinação e } \\
\text { multiplicação in vitro de teca (Tectona } \\
\text { grandis L.f.) a partir de genótipos da } \\
\text { Amazônia Sul-Ocidental. }\end{array}$ & $\begin{array}{l}\text { Acre, } \\
\text { Brasil }\end{array}$ \\
\hline Nor Aini et al. 2009 & $\begin{array}{l}\text { The effects of different indole-3-butyric } \\
\text { acid (IBA) concentrations, two light } \\
\text { regimes of in vitro rooting and } \\
\text { acclimatization of in vitro teak (Tectona } \\
\text { grandis L.f) plantlets }\end{array}$ & $\begin{array}{l}\text { Malaysia, } \\
\text { Índia }\end{array}$ \\
\hline Andrade 2010 & $\begin{array}{l}\text { Indução do rejuvenescimento de teca } \\
\text { (Tectona grandis L. f) através de enxertia } \\
\text { seriada e micropropagação. }\end{array}$ & $\begin{array}{l}\text { Mato Grosso, } \\
\text { Brasil }\end{array}$ \\
\hline
\end{tabular}




\section{CONCLUSÕES}

A literatura pertinente ao cultivo "in vitro" de teca mostrou que as pesquisas, em sua maioria, determinaram o melhor protocolo de micropropagação para a teca, avaliando as fases de assepsia, multiplicação e enraizamento em laboratório ou viveiro, buscando, dessa forma, a melhor maneira de obter um grande número de indivíduos em menor espaço de tempo.

A produção de mudas clonais de teca para plantios florestais constitui-se em um promissor avanço da biotecnologia para o Brasil, contudo ainda carece de incentivo à pesquisa e divulgação dos resultados, visando progresso e melhoria das técnicas utilizadas.

\section{REFERÊNCIAS BIBLIOGRÁFICAS}

ABRAF - ASSOCIAÇÃO BRASILEIRA DE PRODUTORES DE FLORESTAS PLANTADAS. 2009. Anuário estatístico da ABRAF: ano base 2008. Brasília, DF, 120 p.

ABDELNOUR, A., MUÑOS, A. 2005. Micropropagación de teca (Tectona grandis L.f.). Kurú:

Revista Florestal, Costa Rica, v. 2, n. 5. AKRAM, M., AFTAB, F. 2009. An efficient method for clonal propagation and in vitro establishment of softwood shoots from epicormic buds of teak (Tectona grandis L.). Forestry Studies in China, v. 11, n. 2 , p. 105-110.

ANDRADE, S.R.M. 2002. Princípios da cultura de tecidos vegetais. Planaltina, Embrapa

Cerrados, 16p.

ANDRADE, W.F. 2010. Indução do rejuvenescimento de teca (Tectona grandis L. f) através de enxertia seriada e micropropagação. Tese (Doutorado). Escola Superior de Agricultura "Luiz de Queiroz", São Paulo, Piracicaba, 75p.
ANGELI, A.; STAPE, J.L. 2003. Identificação de espécies florestais: Tectona grandis (teca). Piracicaba: Copyright, IPEF. Disponível em: http://www.ipef.br/identificacao/tect ona.grandis.asp Acesso em: 10/10/2010.

BALOONI, K. 1999. Teak investment programmes: Indian perspective. Unasylva, v. 51, n. 201, p. 83-94.

BANDEIRA, J.M.; LIMA, C.S.M.; RUBIN, S.; RIBEIRO, M.V.; FALQUETO, A.R.; PETERS, J.A.; BRAGA, E.J.B. 2007. Diferentes tipos de vedação dos frascos e concentrações de sacarose na micropropagação de Thymus vulgaris L. Revista Brasileira de Biociências, Porto Alegre, v. 5, supl. 2, p. 472-474.

BANIJBTHATANA, D. 1957. Teak forests of Thailand. Tropical Silviculture. Roma, v. 13, n.2, p.193-205.

BERG, T. 1953. A madeira e sua utilização nas construções navais. Anuário Brasileiro de Economia Florestal. Rio de Janeiro, v.3, n.6, p.50-51.

CÁCERES FLORESTAL S/A. 2000. Manual do reflorestamento da Teca. 2 ed. Cáceres: Cáceres Florestal, 38p.

CÁCERES FLORESTAL S/A. 2005. Plano de manejo florestal sustentável Resumo. Disponível em: http://www.caceresflore stal.com.br/assets/plano_manejo_resum o.pdf Acesso em: 12/09/2011.

CALDAS, L.S., HARIDASAN, P., FERREIRA, M.E. 1990. Meios nutritivos. In: TORRES, A.C., CALDAS, L.S. Técnicas e aplicações da cultura de tecidos de plantas. Brasília: ABCTP, EMBRAPA-CNPH, p. 37-70.

CALDEIRA, S.F., OLIVEIRA, D.L.C. 2008. Desbaste seletivo em povoamentos de Tectona grandis com diferentes idades. Acta Amazonica, Manaus, v. 38, n. 2.

CATTELAN, L.V.; STEIN, V.C.; SOUZA, S.A.; HEIDEN, G.; BÜTTOW, M.V.; 
BOBROWSKI, V.L. 2007. Estabelecimento in vitro de Matricaria recutita utilizando diferentes condições de cultivo. Revista Brasileira de Biociências, Porto Alegre, v. 5, supl. 2, p. 201-203.

CARVALHO, J.M.F.C., VIDAL, M.S. 2003. Noções de cultivo de tecidos vegetais. Campina Grande, Embrapa Algodão, 39p.

CORREIA, D. 1993. Crescimento e desenvolvimento de gemas na multiplicação de Eucalyptus spp. in vitro em meio de cultura líquido e sólido. Dissertação - ESALQ, Piracicaba, 113p.

COSTA, R.B.; RESENDE, M.D.V.; SILVA, V.S.M. 2007. Experimentação e seleção no melhoramento genético de Teca (Tectona grandis L.f.). Floresta e Ambiente, v.14, n.1, p. 76-92.

DAQUINTA, M.; RAMOS, L; CAPOTE, I.; LEZCANO, Y.; RODRÍGUEZ, R.; TRINA, D.; ESCALONA, M. 2001. Micropropagación de la teca (Tectona grandis L.F.). Revista Florestal Centroamericana, Comunicación técnica, n. 35, p. 25-28.

ENTERS, T. 1999. Site, technology and productivity of teak plantations in Southeast Asia. Unasylva, v. 51. n. 201, p.55-61.

FERMINO JUNIOR, P.C.P.; NAGAO, E.O.; PEREIRA, J.E.S. 2009. Estabelecimento, germinação e multiplicação in vitro de teca (Tectona grandis L.f.) a partir de genótipos da Amazônia Sul-Ocidental. Scientia Forestalis, Piracicaba, v. 37, n. 84, p. 427-435.

FERNANDES, D. A. ; DIGNART, S. L. ; NOETZOLD, R. 2009. Cultivo in vitro de Tectona grandis L.f. submetido a diferentes tipos de vedação dos frascos e concentrações de sacarose. In: III Semana da Agronomia - I Simpósio de Iniciação Científica em Ciências
Agrárias, Alta Floresta. Resumo Expandido..., p. 101-104. (CD-ROM)

FIGUEIREDO, E.O. 2001. Reflorestamento com Teca (Tectona grandis L.f.) no Estado do Acre. Rio Branco: Embrapa Acre, 28 p.: il. - (Embrapa Acre. Documentos, 65).

FIGUEIREDO, E.O.; OLIVEIRA, L.C., BARBOZA, L.K. 2005. Teca (Tectona grandis L.f.): principais perguntas do futuro empreendedor florestal. Rio Branco: Embrapa Acre, 87p. il. Color. (Embrapa Acre. Documentos, 97).

GRATTAPAGLIA, D., MACHADO, M.A. 1998. Micropropagação. In: TORRES, A.C.,

CALDAS, L.S., BUSO, J.A. Cultura de tecidos e transformação genética de plantas. Brasília: Embrapa - SPI / Embrapa-CNPH, v. 1, p. 183-260.

GYVES, E.M., ROYANI, J.I.; RUGINI, E.. 2007. Efficient method of micropropagation and in vitro rooting of teak (Tectona grandis L.) focusing on large-scale industrial plantations. Annals of Forest Science, 64: 73-78.

HIGASHI, E.N. SILVEIRA, R. L.V.A.; GONÇALVES, A.N. 2000. Propagação vegetativa de Eucalyptus: princípios básicos e a sua evolução no Brasil. Circular técnica IPEF, Piracicaba, n.192.

HIGUCHI, N. 1979. Informações básicas para o manejo florestal da Tectona grandis (Teca)

introduzida no Alto Jauru. Universidade Federal de Mato Grosso, Departamento de Engenharia Florestal. Cuiabá, 92p.

JACOBS, M.R. 1973. Desenvolvimento e pesquisa florestal no Brasil. PNUD/FAO/IBDF/BRA-45. Série Técnica/IBDF. Rio de Janeiro, 150p.

KEW. 2009. Lamiaceae (Labiatae). Kew: Royal Botanic Gardens. Disponível em: http://www.kew.org/science/lamiac eae.html Acesso em: 15/09/2010. 
KILLMANN, W., HONG, L.T. 1999. Rubberwood - the success of an agricultural by product.Unasylva, v. 51, n. 201, p. 66-72.

KRISHNAPILLAY, B. 1999. Silviculture and management of teak plantations. Unasylva, v. 51,n. 201, p. 14-21.

KUSHALKAR, R., SHARON, M. 1996. Direct and indirect somatic embryogenesis of teak

(Tectona grandis L.). Current Science, Bangalore, v. 71, p. 712-715.

LLOID, G., MCCOWN, B. 1980. Commercially feasible micropropagation of mountain laurel,

Kalmia latifolia, by use of shoot-tip culture. Combined Proceedings International Plant Propagators Society, Carlisle, v. 30, p. 421-427.

MACEDO, R.L.G.; GOMES, J.E.; VENTURIN, N.; SALGADO, B.G. 2005. Desenvolvimento inicial de Tectona grandis L. F. (Teca) em diferentes espaçamentos no município de Paracatu, MG. Cerne, Lavras, v. 11, n. 1, p. 61-69.

MALDANER, J.; NICOLOSO; F.T.; SANTOS, E.S.; FAGUNDES; C.K.; FLORES, R.; JUCOSKI, G.O.; SKREBSKY, E.C. 2006. Sacarose e nitrogênio na multiplicação in vitro de Pfaffia glomerata (Spreng.)

Pedersen. Ciência Rural, Santa Maria, v. 36, n. 4, p. 1201-1206.

MALDANER, J.; NICOLOSO; F.T.; SANTOS, E.S.; FAGUNDES; C.K.; FLORES, R.; JUCOSKI, G.O.; SKREBSKY, E.C. 2007. Crescimento de plântulas de Pfaffia glomerata (Spreng.) Pedersen cultivadas in vitro sob dois níveis de nitrogênio e sacarose, durante seis subculturas sucessivas e aclimatização. Ciência Rural, Santa Maria, v. 37, n. 1.

MATRICARDI, W.A.T. 1989. Efeitos dos fatores do solo sobre o desenvolvimento da teca
(Tectona grandis L.F.) cultivada na Grande Cáceres - Mato Grosso. Dissertação (Mestrado). Piracicaba, ESALQ, 135p.

MELLO, H.A. 1963. Alguns aspectos da introdução da teca (Tectona grandis L.F.) no Brasil.

Anuário Brasileiro de Economia Florestal. Rio de Janeiro, v.15, n.15, p.113-119.

MITTELMAN, A. 1999. Teak planting by smallholders in nakhon Sawan, Thailand. Unasylva, n. 201.

MONTEUUIS, O., MAITRE, H.F. 2007. Advances in teak cloning. ITTO Tropical Forest update, Yokohama, v.17, n.3, p.13-15.

MURASHIGE, T., SKOOG, F. 1962. A revised medium for rapid growth and bioassays with

tobacco tissue cultures. PhysiologiaPlantarum, Copenhagen, v. 15, p. 473-497.

NAGAO, E.O.; PASQUAL, M.; RAMOS, J.D. 1994. Efeitos da sacarose e do nitrogênio inorgânico sobre a multiplicação "in vitro" de brotações de porta-enxerto de citros. Bragantia, Campinas, v. 53, n. 1, p. 25-31.

NICOLOSO, F.T.; ERIG, A.C.; RUSSOWSKI, D.; MARTINS, C.F. 2003. Efeito de doses e fontes de carboidratos no crescimento de plantas de ginseng brasileiro (Pfaffia glomerata (Spreng.) Pedersen) cultivadas in vitro. Ciência e Agrotecnologia, Lavras, v. 27, n. 1, p. 84-90.

NICOLOSO, F. T.; ERIG, A. C.; MARTINS, C. F.; RUSSOWSKI, D. 2001. Micropropagação do ginseng brasileiro [Pfaffia glomerata (Spreng.) Pedersen]. Revista Brasileira de Plantas Medicinais, Botucatu, v. 3, n. 2, p. 11-18.

NOR AINI, A. S.; GOH, B. L.; RIDZUAN, R. 2009. The effects of different indole- 
3-butyric acid (IBA) concentrations, two light regimes of in vitro rooting and acclimatization of in vitro teak (Tectona grandis L.f) plantlets. African Journal of Biotechnology v. 8, n.22, p. 61586161.

PALANISAMY, K.; GIREESAN, K.; NAGARAJAN, V.; HEGDE, M. 2009.

Selection and clonal multiplication of superior trees of teak (Tectona grandis) and preliminary evaluation of clones. Journal of Tropical Forest Science, v. 21, n.2, p. 168-174.

PANDEY, D., BROWN, C. 1999. Teak: a global overview. Unasylva, n. 201, v.51, p. 3-13.

RAMAKRISHNA, A. 1978. Farewell to teak. Indian Forester. Dehra Dun, v. 104, n. 9, p. 646-647.

RODRÍGUEZ, R.; CAPOTE, I.; RAMOS, L.; LEZCANO,Y.; ESCALONA, M.; DAQUINTA, M. 2002 Morfogénesis in vitro de teca (Tectona grandis L.). Investigación Agraria: sistemas y recursos forestales, v. 11, n. 1 .

ROMIO, D.L. 2006. Floresteca fecha plantio em 3 mil hectares. Informativo Floresteca.

Disponível em: http://www.floresteca.com.br/news.asp. Acesso em: 11 out. 2006.

ROSERO, N.C., RAMOS, L. 1998. Micropropagação clonal in vitro de árvores selecionadas de Tectona grandis L. (Teca). Disponível em: http://www.uteq.edu.ec/u_investigac ion/biotecnologia/5.pdf Acesso em: 10/10/2010.

SCHUBERT, T.H. 1974. Teak: Tectona grandis L.F. In: USDA. Forest Service. Seeds of Woody

Plants in the United States. Washington, p.803-804.

SHIRIN, F.; RANA, P.K.; MANDAL, A.K. 2005. In vitro clonal propagation of mature Tectona grandis through axillary bud proliferation. Journal of forest research, v. 10, p. 465-469.

SILVA, A.L.L.; FRANCO, E.T.H.; WALTER， J.M.; BISOGNIN， D.A.; CALGAROTO, S.N. 2006. Aclimatização de clones de Dyckia marítima em diferentes substratosBromeliaceae. Revista Brasileira de Agrociência, Pelotas, v. 12, n. 4, p. 495498.

SKREBSKI, E.C.; NICOLOSO, F.T.; FERRÃO, G.E.. 2004. Sacarose e período de cultivo in vitro na aclimatização ex vitro de ginseng brasileiro (Pfaffia glomerata (Spreng.) Pedersen). Ciência Rural, Santa Maria, v. 34, n. 5, p. 1471-1477.

SORACE, M.; FARIA, R.T.; YAMAMOTO, L.Y.; SCHNITZER, J.A.; TAKAHASHI, L.S.A. 2007. Influência de auxina na aclimatização de Oncidium baueri (Orchidaceae). Semina: Ciências Agrárias, Londrina, v. 38, n. 2, p. 195-200.

TAMBARUSSI, $\quad$ E.V. 2009. Desenvolvimento de metodologias biotecnológicas para a micropropagação, regeneração e transformação genética de teca (Tectona grandis L. f) visando resistência a Hyblaea puera. Dissertação (Mestrado - Ciências). Escola Superior de Agricultura "Luiz de Queiroz", São Paulo, Piracicaba, 122p.

TIWARI, S.K.; TIWARI, K.P.; SIRIL, E.A. 2002. An improved micropropagation protocol for teak. Plant Cell, Tissue and Organ Culture, Gordrech, n.71, p. $1-6$.

TONINI, H.; COSTA, M.C.G; SCHWENGBER, L.A.M. 2009. Crescimento da teca (Tectona grandis) em reflorestamento na Amazônia Setentrional. Pesquisa Florestal Brasileira, Colombo, n. 59, p. 05-14. VIANA, A.M.; MAZZA, M.C.; MANTELL, S. 1999. Applications of biotechnology 
for the conservation and sustainable exploitation of plants from Brazilian rain forests. In: BENSON, E.E. Plant conservation biotechnology. London: Taylor \& Francis, cap. 6, p.83-95.

XAVIER, A.; OTONI, W. C.; PENCHEL, R. M. 2007. Micropropagação e enxertia in vitro de espécies florestais. In:
BORÉM, A. Biotecnologia Florestal.

Viçosa: UFV, p. 55-74.

YASODHA, R.; SUMATHI, R.; GURUMURTHI, K. 2004. Micropropagation for quality propagule production in plantation forestry. Indian Journal of Biotechnology, Haryana, v. 3 , n. 2, p. 159-170. 